\title{
Disparity Between Two-Dimensional Echocardiographic and Electroanatomic Left and Right Atrial Volumes in Patients Undergoing Catheter Ablation for Long-Standing Persistent Atrial Fibrillation
}

\author{
L. ŠKŇOUŘIL ${ }^{1}, \check{S ̆}_{\text {. HAVRÁNEK }}{ }^{2}$, V. BULKOVÁ ${ }^{2}$, M. DORDA ${ }^{1}$, T. PALEČEK ${ }^{2}$, J. ŠIMEK $^{2}$, \\ Z. FINGROVÁ ${ }^{2}$, A. LINHART ${ }^{2}$, J. JANUŠKA ${ }^{1}$, D. WICHTERLE ${ }^{2,3}$, M. FIALA ${ }^{1,4}$
}

${ }^{1}$ Department of Cardiology, Hospital Podlesí, Třinec, Czech Republic, ${ }^{2}$ Second Department of Medicine, Department of Cardiovascular Medicine, First Faculty of Medicine, Charles University and General University Hospital, Prague, Czech Republic, ${ }^{3}$ Department of Cardiology, Institute for Clinical and Experimental Medicine, Prague, Czech Republic, ${ }^{4}$ Department of Medicine and Cardiology, University Hospital, Masaryk University, Brno, Czech Republic

Received February 3, 2016

Accepted August 5, 2016

On-line December 16, 2016

\section{Summary}

Left atrial (LA) volume (LAV) is used for the selection of patients with atrial fibrillation (AF) to rhythm control strategies. Calculation of LAV from the LA diameters and areas by two-dimensional (2D) echocardiography may result in significant error. Accuracy of atrial volume assessment has never been studied in patients with long-standing persistent AF (LSPAF) and significant atrial remodeling. This study investigated correlation and agreement between 2D echocardiographic (Simpson method) and electroanatomic (CARTO, Biosense Webster) left and right atrial (RA) volumes (LAV $\mathrm{ECHO}_{\text {VS. }} \mathrm{LAV}_{\text {CARTO }}$ and RAV $\mathrm{V}_{\mathrm{ECHO}}$ vs. RAV $_{\text {CARTO }}$ ) in patients undergoing catheter ablation for LSPAF. The study enrolled 173 consecutive subjects (females: $21 \%$, age: $59 \pm 9$ years). There was only modest correlation between $\operatorname{LAV}_{\text {ECHO }}(92 \pm 31 \mathrm{ml})$ and $\operatorname{LAV}_{\text {CARTO }}(178 \pm 37 \mathrm{ml})(\mathrm{R}=0.57)$, and $\operatorname{RAV}_{\text {ECHO }}(71 \pm 29 \mathrm{ml})$ and $\operatorname{RAV}_{\text {CARTO }}(173 \pm 34 \mathrm{ml}) \quad(\mathrm{R}=0.42)$, respectively. $L A V_{\text {ECHO }}$ and $R A V_{\text {ECHO }}$ underestimated $L A V_{\text {CARTO }}$ and $\operatorname{RAV}_{\text {CARTO }}$ with the absolute bias ( \pm 1.96 standard deviation) of $-85(-148 ;-22) \mathrm{ml}$ and $-102(-169 ;-35) \mathrm{ml}$, respectively, and with the relative bias of $-48(-75 ;-21) \%$ and $-59(-88 ;-30) \%$, respectively (all $\mathrm{P}<0.000001$ for their mutual difference). Significant confounders of this difference were not identified. In patients with LSPAF, 2D echocardiography significantly underestimated both LA and RA volumes as compared with electroanatomic reference. This disagreement was independent of clinical, echocardiographic and mapping characteristics.

\section{Key words}

Long-standing atrial fibrillation - Echocardiography - Atrial volume • Electroanatomic mapping

\section{Corresponding author}

M. Fiala, Department of Internal Medicine and Cardiology, University Hospital Brno, Jihlavská 53, Brno, 659 91, Czech Republic. Fax: +420532232162. E-mail: martin.fiala@gmail.com

\section{Introduction}

Atrial fibrillation (AF) is frequently associated with left atrial (LA) enlargement which is also an acknowledged marker of resistance to pharmacological and non-pharmacological treatment of AF (Berruezo et al. 2007, Hof et al. 2009b, Montefusco et al. 2010, Von Bary et al. 2012, Zhuang et al. 2012). Although LA antero-posterior diameter in long-axis parasternal (PLAX) view has been largely used as a simple index of the LA size, its correlation with the LA volume (LAV) was poor in multiple prior studies (Lester et al. 1999, Pritchett et al. 2003, Badano et al. 2008, Hof et al. 2009a). Three-dimensional (3D) echocardiography, computed tomography (CT) or magnetic resonance (MR) imaging are not commonly used in routine clinical practice for more accurate 
assessment of LAV (Russo et al. 2010, Miyasaka et al. 2011, Mor-Avi et al. 2012, Shimada and Shiota 2012, Koka et al. 2012, Patel et al. 2003, Müller et al. 2010, Vandenberg et al. 1995, Rodevan et al. 1999, Maceira et al. 2010, Abhayaratna et al. 2006, Lang et al. 2005, Havranek et al. 2016). On the other hand, routinely employed automated algorithms for calculation of LAV from the LA diameters and areas by two-dimensional (2D) echocardiography may result in significant error.

Electroanatomic mapping in patients undergoing catheter ablation for $\mathrm{AF}$ offers an alternative tool of 3D atrial reconstruction and volume assessment independent of geometric assumptions (Patel et al. 2003, Müller et al. 2010). The LAV derived from electroanatomic mapping $\left(\mathrm{LAV}_{\text {CARTO }}\right)$ poorly corresponded with 2D-echocardiographic LAV $\left(\mathrm{LAV}_{\mathrm{ECHO}}\right)$ in patients ablated for predominantly paroxysmal AF in prior studies (Patel et al. 2003, Havranek et al. 2016). However, no prior study compared $\mathrm{LAV}_{\mathrm{CARTO}}$ and $\mathrm{LAV}_{\mathrm{ECHO}}$ in the subjects with longstanding persistent AF (LSPAF), the most difficult-toablate AF type because of extensive LA remodeling. In addition, although arrhythmogenic substrate of LSPAF involves RA in up to $30 \%$ of cases (Rostock et al. 2008, Narayan et al. 2012, Haissaguerre et al. 2014), RA is not routinely mapped during $\mathrm{AF}$ ablation and correspondence between 2D echocardiographic and electroanatomic RA volumes $\left(\mathrm{RAV}_{\mathrm{ECHO}}\right.$ and $\left.\mathrm{RAV}_{\mathrm{CARTO}}\right)$ is generally unknown.

This study aimed at investigating the relationship between the $2 \mathrm{D}$ echocardiographic $\mathrm{LAV}_{\mathrm{ECHO}}$ and $\mathrm{RAV}_{\mathrm{ECHO}}$ calculated by the Simpson method and the LAV $_{\text {CARTO }}$ and RAV $\mathrm{V}_{\text {CARTO }}$ derived from $3 \mathrm{D}$ electroanatomic mapping in patients undergoing catheter ablation for LSPAF.

\section{Methods}

\section{Study population}

The study included 173 consecutive patients who underwent their first ablation for LSPAF between August 2007 and December 2011 and met the following criteria: 1) age $18-80$ years; 2) symptomatic LSPAF lasting $>12$ months without intervening sinus rhythm; 3) refractory to oral amiodarone; 4) resistant to electrical cardioversion or recurring within 7 days after. Ethical approval was obtained for the study protocol, and all patients gave written informed consent.

\section{Electroanatomic mapping}

Electroanatomic LA and RA maps (CARTO, Biosense Webster, Diamond Bar, CA, USA) were acquired during $\mathrm{AF}$ by mapping/ablation catheter with a 3.5-mm irrigated-tip electrode (NaviStar ThermoCool, Biosense Webster, Diamond Bar, CA, USA). The maps were based on 3D virtual LA/RA shells reconstructed by software interpolations over the co-ordinates of multiple endocardial points. Efforts were made to obtain highdensity maps consisting of evenly distributed contact points. Transition of the tubular segment of pulmonary vein (PV) into the PV antrum was identified by combined information obtained from fluoroscopy, recording of $\mathrm{PV}$ and LA potentials, and impedance drop. Intracardiac echocardiography assisted in visualization of critical atrial structures in a majority of cases. The LAV $V_{\text {CARTO }}$ and RAV $_{\text {CARTO }}$ were automatically derived from $3 \mathrm{D}$ electroanatomic maps that comprised broader PV antra and entire appendages. The CT image was registered in the electroanatomic map by an automated algorithm that minimizes the distance between mapping points and the CT surface. The match between both merged maps was optimized by eliminating inner and outer electroanatomic points due to inadequate contact or excessive pressure against the atrial wall as well as respiration-related shifts. $\mathrm{LAV}_{\text {CARTO }}$ and $\mathrm{RAV}_{\text {CARTO }}$ were automatically provided by a built-in computation function of the Biosense system. In addition to volume assessment, the proportions of mapping points arbitrarily divided into 3 groups exhibiting voltage $<0.2 \mathrm{mV}$ (severe interstitial fibrosis), 0.2-1.0 mV, and $>1 \mathrm{mV}$ (normal atrial myocardium) were obtained as described previously (Fiala et al. 2010).

\section{Echocardiographic examination}

Transthoracic echocardiography using an echocardiograph iE 33 (Phillips, Bothell, WA, USA) were completed by 3 experienced physicians prior to the ablation according to the guidelines (Pritchett et al. 2003, Abhayaratna et al. 2006, Lang et al. 2005). Left ventricular diameters were measured in PLAX view using M-mode when possible, or 2D echocardiography if more accurate. Antero-posterior LA diameter in PLAX view, and LA and RA long- and short-axis diameters in apical four-chamber $(\mathrm{A} 4 \mathrm{CH})$ and apical two chamber $(\mathrm{A} 2 \mathrm{CH})$ views were measured as the maximum end-systolic linear dimensions not including venous ostia or appendages. Atrial volumes were automatically obtained by biplane $(\mathrm{A} 2 \mathrm{CH}$ and $\mathrm{A} 4 \mathrm{CH})$ and single-plane (A4CH) modified Simpson method for $\mathrm{LAV}_{\mathrm{ECHO}}$ and $\mathrm{RAV}_{\mathrm{ECHO}}$, respectively (Lang et al. 2005). 


\section{Statistical analysis}

Continuous variables were expressed as a mean with standard deviation and compared by 2-tailed t-test for independent samples. Categorical variables were expressed as a percentage and compared by $\chi^{2}$-test. Pearson's correlation and multivariate linear regression were used to analyze the relationship between $\mathrm{LAV}_{\mathrm{ECHO}}$ and $\mathrm{RAV}_{\mathrm{ECHO}}$ together with other clinical covariates as independent variables and $\mathrm{LAV}_{\text {CARTO }}$ and $\mathrm{RAV}_{\text {CARTO }}$ as dependent variable. Stepwise forward method was used for all variables with univariate relationship of $\mathrm{P} \leq 0.20$. The agreement between atrial volumes was analyzed using the modified method of Bland-Altman assuming that LAV $V_{\text {CARTO }}$ and $R A V_{\text {CARTO }}$ are substantially more accurate than $\mathrm{LAV}_{\mathrm{ECHO}}$ and $\mathrm{RAV}_{\mathrm{ECHO}}$. P-value $<0.05$ was considered significant. All analyses were performed using the STATISTICA vers. 12 software (Statsoft, Inc., Tulsa, USA).

\section{Results}

Baseline characteristics of the study population are shown in Table 1. Pre-ablation $\mathrm{LAV}_{\mathrm{ECHO}}$ and $\mathrm{LAV}_{\text {CARTO }}$ were compared in all 173 patients; comparison of RAV $\mathrm{RCHO}_{\mathrm{ECH}}$ and $\mathrm{RAV}_{\mathrm{CARTO}}$ was available in 169 patients. Echocardiographic and electroanatomic mapping parameters are summarized in Tables 2 and 3. The distribution of $\operatorname{LAV}_{\mathrm{ECHO}}(92 \pm 31 \mathrm{ml}) / \mathrm{RAV}_{\mathrm{ECHO}}$ $(71 \pm 29 \mathrm{ml})$ and LAV $_{\text {CARTO }}(178 \pm 37 \mathrm{ml}) / \mathrm{RAV}_{\text {CARTO }}$ $(173 \pm 34 \mathrm{ml})$ is shown in Figure 1.

There was only modest correlation between $\mathrm{LAV}_{\mathrm{ECHO}}$ and $\mathrm{LAV}_{\text {CARTO }}(\mathrm{R}=0.57)$, and $\mathrm{RAV}_{\mathrm{ECHO}}$ and RAV $_{\text {CARTO }}(\mathrm{R}=0.42)$, respectively $(\mathrm{P}<0.0001$ for both coefficients) (Fig. 2). $\mathrm{LAV}_{\mathrm{ECHO}}$ and $\mathrm{RAV}_{\mathrm{ECHO}}$ underestimated $\mathrm{LAV}_{\mathrm{CARTO}}$ and $\mathrm{RAV}_{\mathrm{CARTO}}$ with the absolute bias $( \pm 1.96$ standard deviation) of $-85(-148 ;-22) \mathrm{ml}$ and $-102(-169 ;-35) \mathrm{ml}$, respectively, and with the relative bias of $-48(-75 ;-21) \%$ and $-59(-88 ;-30) \%$, respectively (all $\mathrm{P}<0.000001$ for their mutual difference) (Fig. 3). The proportions of patients exhibiting difference between echocardiographic and electroanatomic LAV and RAV that exceeded predefined level of error are shown in Table 4. No significant and independent covariates of the difference between $\mathrm{LAV}_{\mathrm{ECHO}}$ and $\mathrm{LAV}_{\text {CARTO }}$ and between $\mathrm{RAV}_{\mathrm{ECHO}}$ and RAV $\mathrm{RARTO}_{\text {(a) }}$ identified by multivariate regression analysis.

\section{Discussion}

This study demonstrated that the LAV derived from electroanatomic endocardial map was approximately twofold larger than that assessed by the 2D echocardiographic Simpson method and, importantly, that the limits of agreement were considerably wide. Such disagreement was for the first time shown in patients with intractable LSPAF and significant left atrial enlargement. This is also the first study that revealed similarly poor correspondence between electroanatomic and echocardiographic RAV.

Table 1. Baseline characteristics.

\begin{tabular}{|c|c|}
\hline Age (years) & $59 \pm 9(32-79)$ \\
\hline Females & $37(21 \%)$ \\
\hline Total AF history (months) & $\begin{array}{c}\text { median } 60, \\
\text { IQR 31-93 }(13-504)\end{array}$ \\
\hline Persistent AF duration (months) & $\begin{array}{c}\operatorname{median} 26, \\
\text { IQR } 17-48(13-254)\end{array}$ \\
\hline Arterial hypertension & $107(62 \%)$ \\
\hline Diabetes mellitus & $20(12 \%)$ \\
\hline Stroke/TIA & $22(13 \%)$ \\
\hline Coronary artery disease & $13(8 \%)$ \\
\hline Pulmonary disease & $21(12 \%)$ \\
\hline History of heart failure & $34(19 \%)$ \\
\hline$L V E F \leq 40 \%$ before ablation & $28(16 \%)$ \\
\hline Hypothyroidism & $13(8 \%)$ \\
\hline $\mathrm{CHADS}_{2}$ & $1.2 \pm 1.0(0-4)$ \\
\hline $\mathrm{CHA}_{2} \mathrm{DS}_{2} \mathrm{VASC}$ & $1.7 \pm 1.4(0-6)$ \\
\hline Body mass index $\left(\mathrm{kg} / \mathrm{m}^{2}\right)$ & $31 \pm 4(19-44)$ \\
\hline LV end-diastolic diameter (mm) & $52 \pm 7(37-79)$ \\
\hline LV end-systolic diameter ( $\mathrm{mm})$ & $37 \pm 8(21-67)$ \\
\hline LVEF (\%) & $\begin{array}{c}\text { median 58, } \\
\text { IQR 51-60 (25-67) }\end{array}$ \\
\hline
\end{tabular}

Data shown as mean \pm standard deviation (range) or median with interquartile range (IQR) (range) or count (percentage). $\mathrm{AF}$ - atrial fibrillation, LV - left ventricular, LVEF - left ventricular ejection fraction, TIA - transitory ischemic attack.

Table 2. Left and right atrial echocardiographic parameters.

$\begin{array}{lc}L A \text { antero-posterior diameter }(\mathrm{mm}) & 48 \pm 5 \\ L A \text { long-axis diameter }(\mathrm{mm}) & 68 \pm 6 \\ L A \text { short axis diameter }(\mathrm{mm}) & 47 \pm 6 \\ R A \text { long-axis diameter }(\mathrm{mm}) & 61 \pm 6 \\ R A \text { short axis diameter }(\mathrm{mm}) & 44 \pm 8 \\ L A V_{E C H O}(\mathrm{ml}) & 92 \pm 31 \\ R A V_{E C H O}(\mathrm{ml}) & 71 \pm 29\end{array}$

Data shown as mean \pm standard deviation (range). LA - left atrial, RA - right atrial, $\mathrm{LAV}_{\mathrm{ECHO}}, \mathrm{RAV}_{\mathrm{ECHO}}$ - left and right atrial volumes assessed by 2D echocardiography (Simpson method). 
Table 3. Left and right atrial electroanatomic mapping parameters.

\begin{tabular}{lc}
\hline LA mapping points & $222 \pm 39$ \\
$R A$ mapping points & $177 \pm 29$ \\
LA points $<0.2 \mathrm{mV}(\%)$ & $24 \pm 18$ \\
LA points $>1.0 \mathrm{mV}(\%)$ & $19 \pm 11$ \\
$R A$ points $<0.2 \mathrm{mV}(\%)$ & $17 \pm 11$ \\
$R A$ points $>1.0 \mathrm{mV}(\%)$ & $35 \pm 16$ \\
LA maximum voltage $(\mathrm{mV})$ & $5.5 \pm 2.4$ \\
$R A$ maximum voltage $(\mathrm{mV})$ & $6.2 \pm 2.5$ \\
LAV CARTO $(\mathrm{ml})$ & $178 \pm 37$ \\
$R A V_{\text {CARTO }}(\mathrm{ml})$ & $173 \pm 34$ \\
\hline
\end{tabular}

Data shown as mean \pm standard deviation (range). LA - left atrial, RA - right atrial, LAV $\mathrm{V}_{\text {CARTO, }} \mathrm{RAV}_{\text {CARTO }}$ - left and right atrial volumes derived from electroanatomic mapping.
Table 4. Proportions of subjects with relative deviation of echocardiographic from electroanatomic atrial volume.

\begin{tabular}{|c|c|c|}
\hline & \multicolumn{2}{|c|}{ LAV $_{\text {ECHO }}$ vs. RAV ECHO vs } \\
\hline & LAV $_{\text {CARTO }}$ & RAV \\
\hline Magnitude of error $>10 \%$ & $99 \%$ & $97 \%$ \\
\hline Magnitude of error $>20 \%$ & $95 \%$ & $97 \%$ \\
\hline Magnitude of error $>30 \%$ & $92 \%$ & $93 \%$ \\
\hline Magnitude of error $>50 \%$ & $46 \%$ & $73 \%$ \\
\hline
\end{tabular}

Results are shown for 4 categories defined by lower limit of error. $\mathrm{LAV}_{\mathrm{ECHO}}, \mathrm{RAV}_{\mathrm{ECHO}}$ - left and right atrial volumes automatically assessed by 2D echocardiography (Simpson method), LAV $\mathrm{V}_{\text {CARTO, }}$ RAV $V_{\text {CARTO }}$ - left and right atrial volumes assessed by electroanatomic mapping.
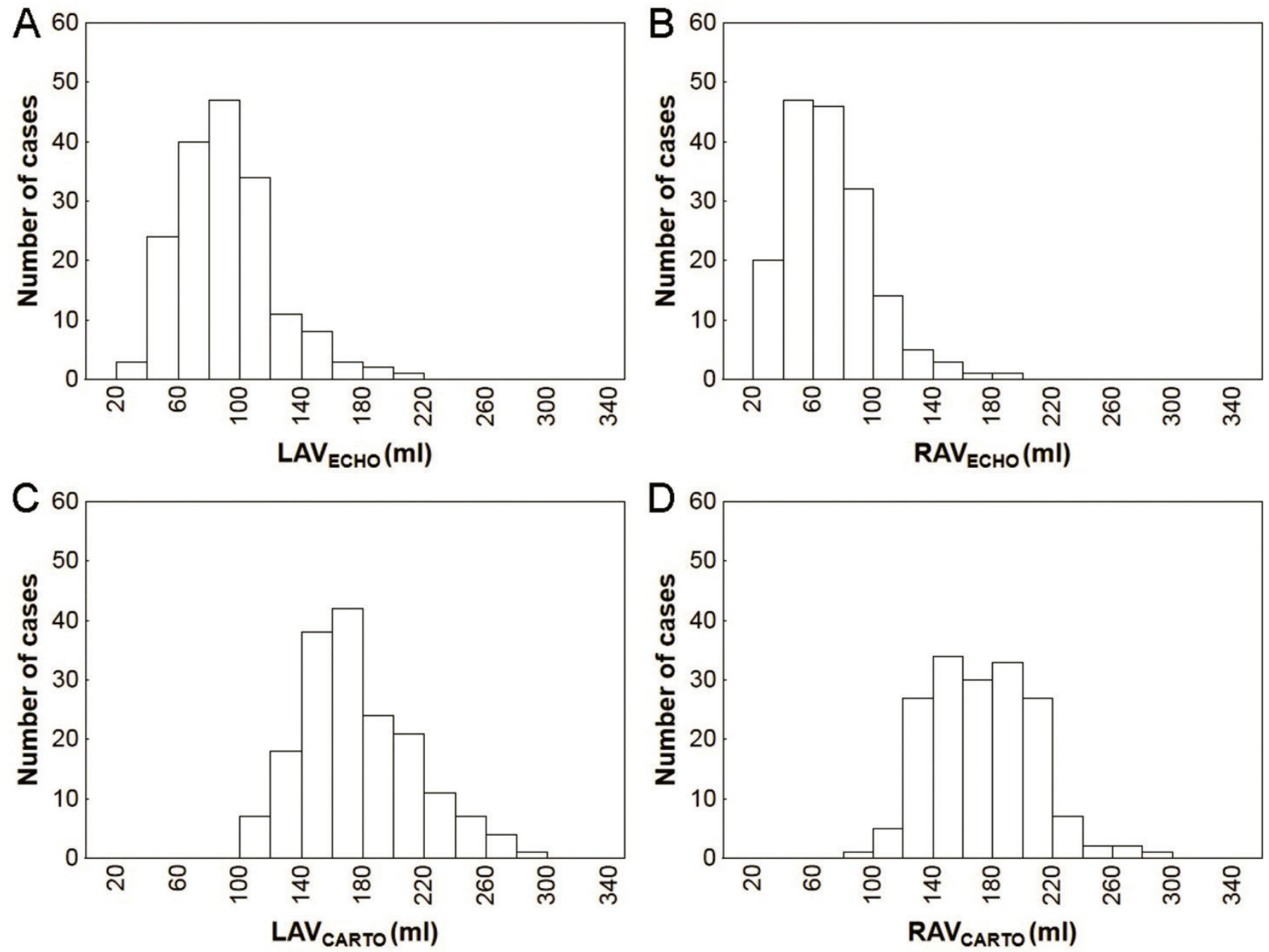

Fig. 1. Distribution of left and right atrial volumes. $L A V_{E C H O}, R A V_{E C H O}$ - left and right atrial volume assessed by $2 D$ echocardiography (Simpson method), LAV $\mathrm{V}_{\text {CARTO, }}$ RAV $\mathrm{V}_{\text {CARTO }}$ - left and right atrial volumes derived from electroanatomic mapping. 

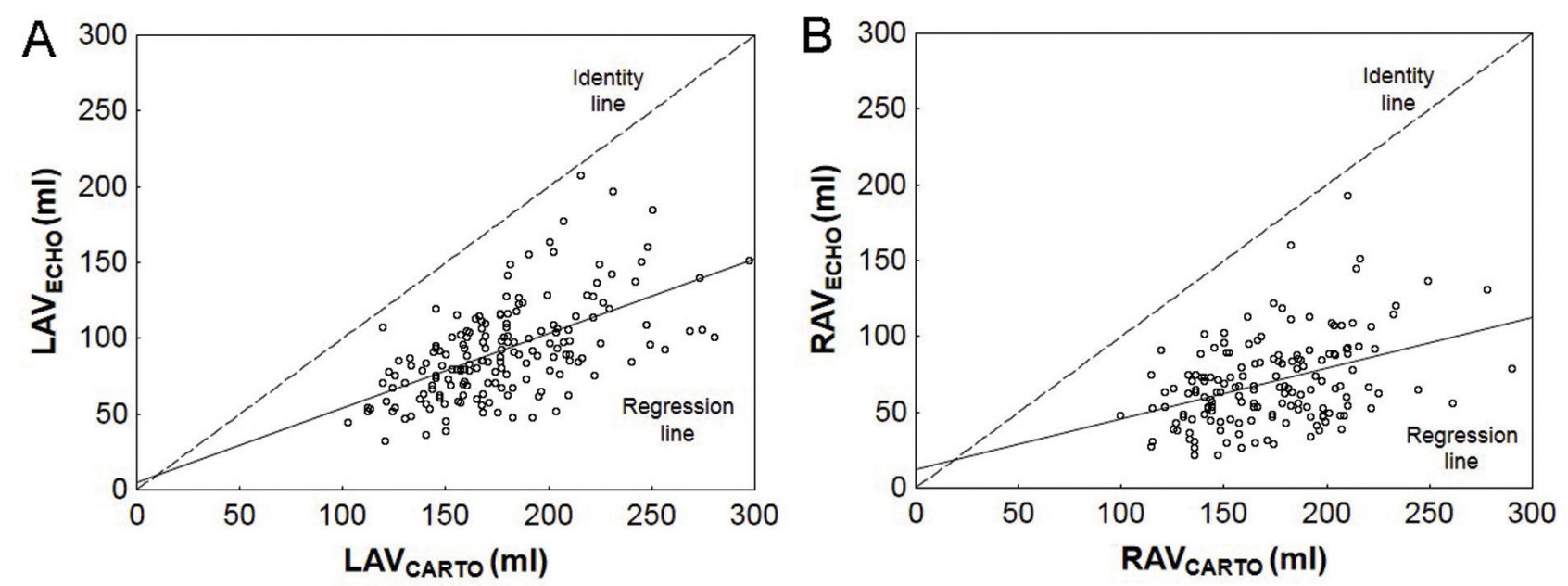

Fig. 2. Pearson's correlation between two-dimensional echocardiographic and electroanatomic volumes. Correlation of left atrial volumes (A) and right atrial volumes (B). Abbreviations as in Figure 1.
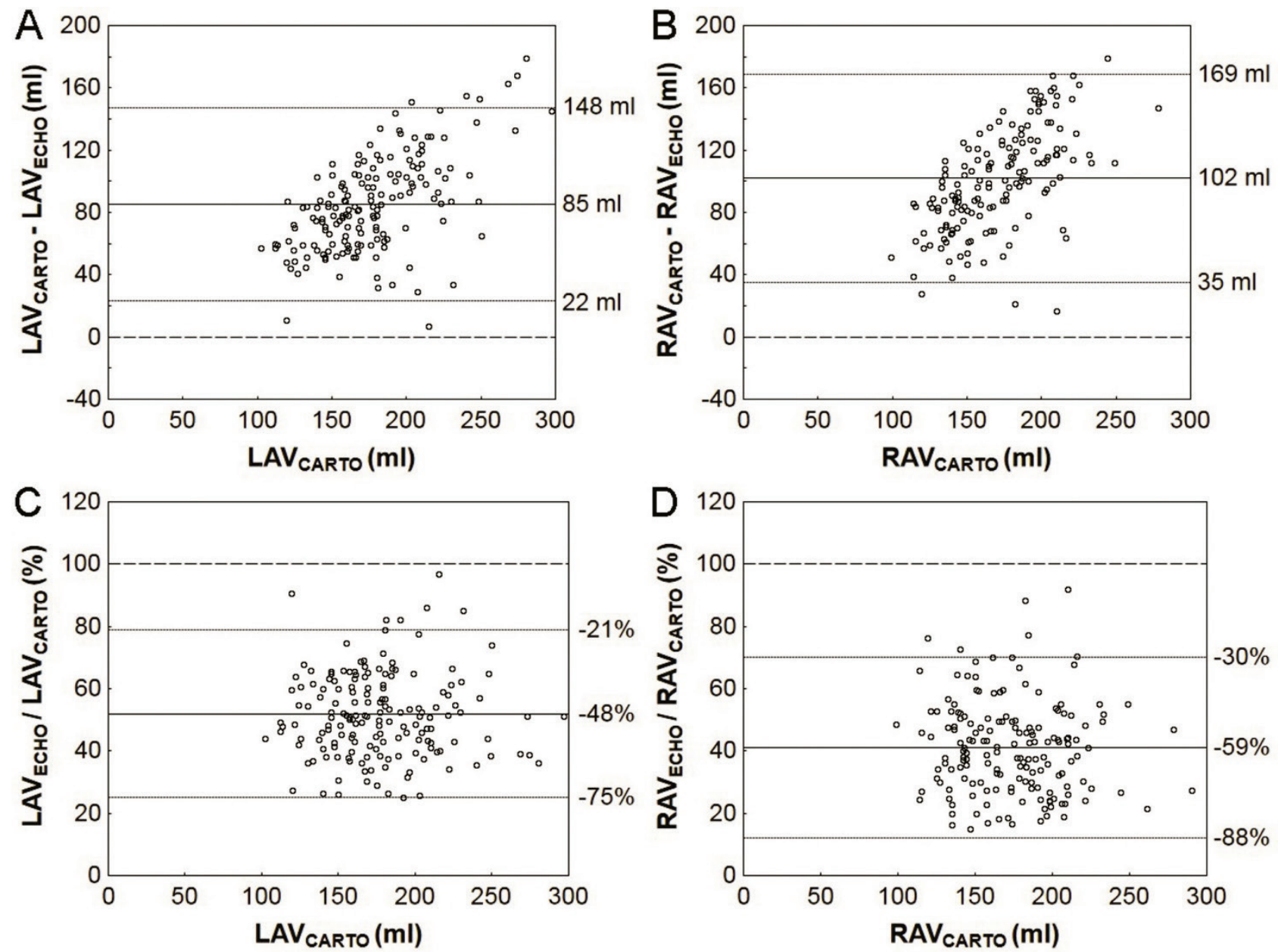

Fig. 3. Agreement between two-dimensional echocardiographic and electroanatomic atrial volumes. Scatterplots for absolute (A and B) and relative (C and $\mathbf{D})$ differences between left atrial $(\mathbf{A}$ and $\mathbf{C})$ and right atrial (B and $\mathbf{D})$ volumes obtained by $2 \mathrm{D}$ echocardiography and electroanatomic mapping. Dashed line - identity line, solid line - bias, dotted line - limits of agreement ( \pm 1.96 standard deviation). Abbreviations as in Figure 1. 
The present study corroborated previously reported systematic underestimation (by $\sim 30 \%$ ) of LAV assessed by $2 \mathrm{D}$ echocardiography when compared with the assessment by CT or MR (Koka et al. 2012, Rodevan et al. 1999). LAV obtained by echocardiographic biplane Simpson method was also lower by $20-30 \%$ when compared with electroanatomic LAV; this study reported excellent correlation $(r=0.9)$ between electroanatomic and echocardiographic LAV; however, it included a relatively small number of patients with only paroxysmal AF (Patel et al. 2003). Our concurrent analysis of a larger population with all AF types showed an increasing scatter of differences between $\mathrm{LAV}_{\mathrm{ECHO}}$ and $\mathrm{LAV}_{\mathrm{CARTO}}$ as well as trend to greater both absolute and relative underestimation of true LA size in patients with excessive LA enlargement (Havranek et al. 2016).

Electroanatomic instead of CT atrial volumes were used in our study. We are convinced that they can be used promiscuously because excellent match between high-density electroanatomic map and CT image can be invariantly achieved during AF ablation procedures. This is supported by prior study which showed that electroanatomic reconstruction could display true LA 3D anatomy as defined by the CT with high accuracy in most of the LA regions (Piorkowski et al. 2006). Recently, the LAV derived from electroanatomic mapping correlated and agreed well with the LAV calculated by MR (Rabbat et al. 2015).

Inaccuracy of $\mathrm{LAV} / \mathrm{RAV}_{\mathrm{ECHO}}$ may be influenced by availability of suitable echocardiographic window, observer-dependent adjustment of angulation and gain for endocardial contour visualization, and correct timing of measurement at the end of ventricular systole (Lester et al. 1999, Ujino et al. 2006). The image quality and anatomically correct projection are frequently competing factors, so that the planes may not be aligned to geometric centre of the chamber in order to achieve maximum cross-sectional area, and biplane assessments may not be strictly orthogonal. Thus, the disparity between the methods might results from: i) failure of simple geometric assumptions applied by 2D echocardiography to assess adequately the true volume of complex atrial shape (Cozma et al. 2007) and/or ii) failure to acquire the proper images for biplane assessment in terms of orthogonality and nice endocardial contour. Although the Simpson method is less dependent on simple geometric assumption (like, for example, prolate ellipsoid method), we believe that both are important sources of error. One can easily imagine that non-spherical structure is prone to either overestimation or underestimation, while more spherical structure is prone to underestimation only. Therefore, bidirectional deviations are mutually cancelled in small, non-spherical atria in patients with paroxysmal AF while unidirectional deviations aggregate in significantly remodeled and more spherically shaped atria in patients with LSPAF. Besides spherical remodeling of the LA (Bisbal et al. 2013), other factors may also play a role: enlargement of the funnelshaped PV antra (Tsao et al. 2001), LA roof reshaping (Kurotobi et al. 2011), and dilation of the anterior LA including the LA appendage (Nedios et al. 2011).

The results of our study are clearly biased by the volume of LA appendage that was mapped, i.e. included into the $\mathrm{LAV}_{\mathrm{CARTO}}$. Biplane $2 \mathrm{D}$ echocardiography does not display LA appendage that was, therefore, principally excluded from the $\mathrm{LAV}_{\mathrm{ECHO}}$ calculation. LA appendage volume ranges between $10-30 \mathrm{ml}$ according to different studies, so that the sizeable difference between $\mathrm{LAV}_{\mathrm{CARTO}}$ and LAV $\mathrm{ECHO}_{\mathrm{E}}$ in our study would hardly have been eliminated if electroanatomic maps had been edited in this respect.

Importantly, there is also bias in the opposite direction that relates to the timing of LAV/RAV assessment. While echocardiographic readings are performed at the end-systolic maximum of atrial volume, the electroanatomic mapping is triggered by the QRS complexes, i.e. points are acquired at the end-diastolic phase when atrial volume is consistently lower by approximately $20-30 \mathrm{ml}$, which may offset the bias related to the LA appendage (see above).

The difference between LAV $\mathrm{LARTO}_{\text {and }}$ $\mathrm{LAV}_{\mathrm{ECHO}}$ was substantially greater than in prior studies and we were not able to find any clinical or morphological variables responsible for this disagreement as in our previous study (Havranek et al. 2016). However, this study investigated a significantly larger and more heterogeneous population of AF patients and consequently was more powered to identify individual confounders.

\section{Limitations}

Because of retrospective nature of our investigation, the study has several limitations:

Readings of CT-derived atrial volumes were not available. We have no centre-specific data on within- and inter-examiner reproducibility of $2 \mathrm{D}$ echocardiographic LAV/RAV. The same applies for LAV/RAV assessed by means of electroanatomic mapping which was performed 
only once per patient by single experienced operator.

Finally, despite limitations of 2D echocardiography for the assessment of atrial volume, the vast majority of prognostic data is derived from this method. Therefore, before adoption of other imaging methods into clinical practice, their prognostic value should be assumed as unknown.

\section{Conclusions}

In patients with LSPAF and significant atrial remodeling, the $2 \mathrm{D}$ echocardiography with the use of single/biplane Simpson method significantly underestimated the atrial size compared to the electroanatomic reference. Therefore, the results of this method should be interpreted with caution, especially when used for selection of suitable candidates for rhythm control strategies including catheter ablation. More focused studies are needed to disclose the main source of inaccuracy in atrial volume assessment by $2 \mathrm{D}$ echocardiography in patients with severe atrial dilation.

\section{Conflict of Interest}

There is no conflict of interest.

\section{Acknowledgements}

Grants of Czech Ministry of Health NR 9143-3/2007 and NS/9684-4/2008.

\section{References}

ABHAYARATNA WP, SEWARD JB, APPLETON CP, DOUGLAS PS, OH JK, TAJIK AJ, TSANG TSM: Left atrial size: physiologic determinants and clinical applications. $J$ Am Coll Cardiol 47: 2357-2363, 2006.

BADANO LP, PEZZUTTO N, MARINIGH R, CINELLO M, NUCIFORA G, PAVONI D, GIANFAGNA P, FIORETTI PM: How many patients would be misclassified using M-mode and two-dimensional estimates of left atrial size instead of left atrial volume? A three dimensional echocardiographic study. $J$ Cardiovasc Med 9: 476-484, 2008.

BERRUEZO A, TAMBORERO D, MONT L, BENITO B, TOLOSANA JM, SITGES M, VIDAL B, ARRIAGADA G, MÉNDEZ F, MATIELLO M, MOLINA I, BRUGADA J: Pre-procedural predictors of atrial fibrillation recurrence after catheter ablation. Eur Heart J 28: 836-841, 2007.

BISBAL F, GUIU E, CALVO N, MARIN D, BERRUEZO A, ARBELO E, ORTIZ-PÉREZ J, DE CARALT TM, TOLOSANA JM, BORRÀS R, SITGES M, BRUGADA J, MONT L: Left atrial sphericity: a new method to assess atrial remodeling. Impact on the outcome of atrial fibrillation ablation. J Cardiovasc Electrophysiol 24: 752-759, 2013.

COZMA D, POPESCU BA, LIGHEZAN D, LUCIAN P, MORNOS C, GINGHINA C, DRAGULESCU SI: Left atrial remodeling: assessment of size and shape to detect vulnerability to atrial fibrillation. Pacing Clin Electrophysiol 30 (Suppl 1): S147-S150, 2007.

FIALA M, WICHTERLE D, CHOVANČÍK J, BULKOVÁ V, WOJNAROVÁ D, NEVŘALOVÁ R, JANUŠKA J: Left atrial voltage during atrial fibrillation in paroxysmal and persistent atrial fibrillation patients. Pacing Clin Electrophysiol 33: 541-548, 2010.

HAISSAGUERRE M, HOCINI M, DENIS A, SHAH AJ, KOMATSU Y, YAMASHITA S, DALY M, AMRAOUI S, ZELLERHOFF S, PICAT MQ, QUOTB A, JESEL L, LIM H, PLOUX S, BORDACHAR P, ATTUEL G, MEILLET V, RITTER P, DERVAL N, SACHER F, BERNUS O, COCHET H, JAIS P, DUBOIS R: Driver domains in persistent atrial fibrillation. Circulation 130: 530-538, 2014.

HAVRANEK S, FIALA M, BULAVA A, SKNOURIL L, DORDA M, BULKOVA V, FINGROVA Z, SOUCKOVA L, PALECEK T, SIMEK J, LINHART A, WICHTERLE D: Multivariate analysis of correspondence between left atrial volumes assessed by echocardiography and 3-dimensional electroanatomic mapping in patients with atrial fibrillation. PLoS One 11: e0152553, 2016.

HOF I, ARBAB-ZADEH A, SCHERR D, CHILUKURI K, DALAL D, ABRAHAM T, LIMA J, CALKINS H: Correlation of left atrial diameter by echocardiography and left atrial volume by computed tomography. J Cardiovasc Electrophysiol 20: 159-163, 2009a. 
HOF I, CHILUKURI K, ARBAB-ZADEH A, SCHERR D, DALAL D, NAZARIAN S, HENRIKSON C, SPRAGG D, BERGER R, MARINE J, CALKINS H: Does left atrial volume and pulmonary venous anatomy predict the outcome of catheter ablation of atrial fibrillation? J Cardiovasc Electrophysiol 20: 1005-1010, 2009b.

KOKA AR, GOULD SD, OWEN AN, HALPERN EJ: Left atrial volume: comparison of 2D and 3D transthoracic echocardiography with ECG-gated CT angiography. Acad Radiol 19: 62-68, 2012.

KUROTOBI T, IWAKURA K, INOUE K, KIMURA R, TOYOSHIMA Y, ITO N, MIZUNO H, SHIMADA Y, FUJII K, NANTO S, KOMURO I: The significance of the shape of the left atrial roof as a novel index for determining the electrophysiological and structural characteristics in patients with atrial fibrillation. Europace 13: 803-808, 2011.

LANG RM, BIERIG M, DEVEREUX RB, FLACHSKAMPF FA, FOSTER E, PELLIKKA PA, PICARD MH, ROMAN MJ, SEWARD J, SHANEWISE JS, SOLOMON SD, SPENCER KT, SUTTON MS, STEWART WJ; CHAMBER QUANTIFICATION WRITING GROUP; AMERICAN SOCIETY OF ECHOCARDIOGRAPHY'S GUIDELINES AND STANDARDS COMMITTEE; EUROPEAN ASSOCIATION OF ECHOCARDIOGRAPHY: Recommendations for chamber quantification: a report from the American Society of Echocardiography's Guidelines and Standards Committee and the Chamber Quantification Writing Group, developed in conjunction with the European Association of Echocardiography, a branch of the European Society of Cardiology. J Am Soc Echocardiogr 18: 1440-1463, 2005.

LESTER SJ, RYAN EW, SCHILLER NB, FOSTER E: Best method in clinical practice and in research studies to determine left atrial size. Am J Cardiol 84: 829-832, 1999.

MACEIRA AM, COSÍN-SALES J, ROUGHTON M, PRASAD SK, PENNELL DJ: Reference left atrial dimensions and volumes by steady state free precession cardiovascular magnetic resonance. J Cardiovasc Magn Reson 12: $65,2010$.

MIYASAKA Y, TSUJIMOTO S, MAEBA H, YUASA F, TAKEHANA K, DOTE K, IWASAKA T: Left atrial volume by real-time three-dimensional echocardiography: validation by 64 -slice multidetector computed tomography. $J$ Am Soc Echocardiogr 24: 680-686, 2011.

MONTEFUSCO A, BIASCO L, BLANDINO A, CRISTOFORETTI Y, SCAGLIONE M, CAPONI D, DI DONNA P, BOFFANO C, CESARANI F, COIN D, PERVERSI J, GAITA F: Left atrial volume at MRI is the main determinant of outcome after pulmonary vein isolation plus linear lesion ablation for paroxysmal-persistent atrial fibrillation. $J$ Cardiovasc Med 11: 593-598, 2010.

MOR-AVI V, YODWUT C, JENKINS C, KÜHL H, NESSER HJ, MARWICK TH, FRANKE A, WEINERT L, NIEL $\mathrm{J}$, STERINGER-MASCHERBAUER R, FREED BH, SUGENG L, LANG RM: Real-time 3D echocardiographic quantification of left atrial volume: multicenter study for validation with CMR. JACC Cardiovasc Imaging 5: 769-777, 2012.

MÜLLER H, BURRI H, GENTIL P, LERCH R, SHAH D: Measurement of left atrial volume in patients undergoing ablation for atrial fibrillation: comparison of angiography and electro-anatomic (CARTO) mapping with realtime three-dimensional echocardiography. Europace 12: 792-797, 2010.

NARAYAN SM, KRUMMEN DE, SHIVKUMAR K, CLOPTON P, RAPPEL WJ, MILLER JM: Treatment of atrial fibrillation by ablation of localized sources: the conventional ablation for atrial fibrillation with and without focal impulse and rotor modulation (CONFIRM) trial. J Am Coll Cardiol 60: 628-636, 2012.

NEDIOS S, TANG M, ROSER M, SOLOWJOWA N, GERDS-LI JH, FLECK E, KRIATSELIS C: Characteristic changes of volume and three-dimensional structure of the left atrium in different forms of atrial fibrillation: predictive value after ablative treatment. $J$ Interv Card Electrophysiol 32: 87-94, 2011.

PATEL VV, REN JF, JEFFERY ME, PLAPPERT TJ, ST JOHN SUTTON MG, MARCHLINSKI FE: Comparison of left atrial volume assessed by magnetic endocardial catheter mapping versus transthoracic echocardiography. Am J Cardiol 91: 351-354, 2003.

PIORKOWSKI C, HINDRICKS G, SCHREIBER D, TANNER H, WEISE W, KOCH A, GERDS-LI JH, KOTTKAMP $\mathrm{H}$ : Electroanatomic reconstruction of the left atrium, pulmonary veins, and esophagus compared with the true anatomy on multislice computed tomography in patients undergoing catheter ablation of atrial fibrillation. Heart Rhythm 3: 317-327, 2006. 
PRITCHETT AM, JACOBSEN SJ, MAHONEY DW, RODEHEFFER RJ, BAILEY KR, REDFIELD MM: Left atrial volume as an index of left atrial size: a population-based study. J Am Coll Cardiol 41: 1036-1043, 2003.

RABBAT MG, WILBER D, THOMAS K, MALICK O, BASHIR A, AGRAWAL A, BISWAS S, SANAGALA T, SYED MA: Left atrial volume assessment in atrial fibrillation using multimodality imaging: a comparison of echocardiography, invasive three-dimensional CARTO and cardiac magnetic resonance imaging. Int $J$ Cardiovasc Imaging 31: 1011-1018, 2015.

RODEVAN O, BJORNERHEIM R, LJOSLAND M, MAEHLE J, SMITH HJ, IHLEN H: Left atrial volumes assessed by three- and two-dimensional echocardiography compared to MRI estimates. Int J Card Imaging 15: 397-410, 1999.

ROSTOCK T, STEVEN D, HOFFMANN B, SERVATIUS H, DREWITZ I, SYDOW K, MÜLLERLEILE K, VENTURA R, WEGSCHEIDER K, MEINERTZ T, WILLEMS S: Chronic atrial fibrillation is a biatrial arrhythmia: data from catheter ablation of chronic atrial fibrillation aiming arrhythmia termination using a sequential ablation approach. Circ Arrhythm Electrophysiol 1: 344-353, 2008.

RUSSO C, HAHN RT, JIN Z, HOMMA S, SACCO RL, DI TULLIO MR: Comparison of echocardiographic singleplane versus biplane method in the assessment of left atrial volume and validation by real time threedimensional echocardiography. J Am Soc Echocardiogr 23: 954-960, 2010.

SHIMADA YJ, SHIOTA T: Underestimation of left atrial volume by three-dimensional echocardiography validated by magnetic resonance imaging: a meta-analysis and investigation of the source of bias. Echocardiogaphy 29: 385-390, 2012.

TSAO HM, YU WC, CHENG HC, WU MH, TAI CT, LIN WS, DING YA, CHANG MS, CHEN SA: Pulmonary vein dilation in patients with atrial fibrillation: detection by magnetic resonance imaging. $J$ Cardiovasc Electrophysiol 12: 809-813, 2001.

UJINO K, BARNES ME, CHA SS, LANGINS AP, BAILEY KR, SEWARD JB, TSANG TS: Two-dimensional echocardiographic methods for assessment of left atrial volume. Am J Cardiol 98: 1185-1188, 2006.

VANDENBERG BF, WEISS RM, KINZEY J, ACKER M, STARK CA, STANFORD W, BURNS TL, MARCUS ML, KERBER RE: Comparison of left atrial volume by two-dimensional echocardiography and cine-computed tomography. Am J Cardiol 75: 754-757, 1995.

VON BARY C, DORNIA C, EISSNERT C, NEDIOS S, ROSER M, HAMER OW, GERDS-LI JH, PAETSCH I, JAHNKE C, GEBKER R, WEBER S, FLECK E, KRIATSELIS C: Predictive value left atrial volume measured by non-invasive cardiac imaging in the treatment of paroxysmal atrial fibrillation. $J$ Interv Card Electrophysiol 34: 181-188, 2012.

ZHUANG J, WANG Y, TANG K, LI X, PENG W, LIANG C, XU Y: Association between left atrial size and atrial fibrillation recurrence after single circumferential pulmonary vein isolation: a systematic review and meta-analysis of observational studies. Europace 14: 638-645, 2012. 